\title{
Neuroticism as a Marker of Vulnerability to COVID-19 Infection
}

\author{
Mohsen Khosravi ${ }^{凶}$ \\ Department of Psychiatry and Clinical Psychology, Zahedan University of Medical Sciences, Zahedan, Iran
}

Serious health threats might be imposed on the members of societies affected by Large-scale public health emergencies, particularly the COVID-19 pandemic. Generally, humans show negative responses to such threats, which may result in less psychological well-being and psychopathology. ${ }^{1}$ Journalists and policy-makers usually put an emphasis on the role of sociodemographic factors for the identification and support of at-risk people (e.g., living alone, elderly). However, previous research has indicated that personality differences would lead to the overprediction of psychological well-being beyond these facets. ${ }^{2}$ Accordingly, it is vitally needed to incorporate personality for the identification of at-risk people.

Individual differences in personality during the COVID-19 pandemic play a key role in adopting the protective behaviors and modulating the relationship between the immune system and stressors. In other word, the subjects' risk perception of a pandemic, immunity, and progression of health problems are highly affected by stable individual differences, including personality traits. ${ }^{3,4}$ However, few studies have been devoted to examine the role of personality traits in predicting virus-mitigating behaviors. ${ }^{5}$ In this letter, i have researched scarce investigative resources in this context to complete measures of association between neuroticism personality trait and the vulnerability to COVID-19 infection.

Neuroticism, known as one of the Big Five personality traits, represents the tendency of individuals towards experiencing negative emotions, including depression, anxiety, and anger. Individuals with high neuroticism scores perceive the world to be threatening, they are quickly distressed, and it is difficult for them to cope with stressful situations. ${ }^{3}$ This argument has

\footnotetext{
Received: May 24, 2020 Revised: June 29, 2020

Accepted: July 1, 2020

$\triangle$ Correspondence: Mohsen Khosravi, MD

Department of Psychiatry and Clinical Psychology, Baharan Psychiatric Hospital, Zahedan University of Medical Sciences, Zahedan 9813913777, Iran

Tel: +98-5433522636, Fax: +98-5433518352

E-mail: dr_khosravi2016@yahoo.com

(ac) This is an Open Access article distributed under the terms of the Creative Commons Attribution Non-Commercial License (https://creativecommons.org/licenses/bync/4.0) which permits unrestricted non-commercial use, distribution, and reproduction in any medium, provided the original work is properly cited.
}

been supported by studies on neuroticism mechanisms, which have highlighted the critical role of affective reactivity and preoccupation processes. In this respect, individuals with high neuroticism might 1) further concern themselves in the COVID19-related information and pandemic consequences (e.g., their health, crisis preoccupation), and 2) experience more adverse impacts during this preoccupation (i.e., affective reactivity). ${ }^{6}$ Consistent with these results, Zajenkowski et al. ${ }^{7}$ and Abdelrahman ${ }^{8}$ demonstrated that the neuroticism personality trait is positively associated with adopting social distancing to avoid COVID-19 infection. Nevertheless, Cowling et al. ${ }^{9}$ showed that high anxiety levels are attributed to less personal protection practices (e.g., handwashing and using face masks) and stricter social distancing for infection avoidance. This behavior contradiction in prone-to-neuroticism people in the face of a pandemic is probably due to their neuroticism levels. For instance, individuals with higher levels of anxiety and fear are more likely to adopt denial as a psychological defense mechanism for the mitigation of their fears. In other words, they practice risky behaviors, such as substance/medication use disorders or risky sexual practices, for feeling secure psychologically. ${ }^{10}$

Moreover, it has been proved that neuroticism can be associated with the immune system in three manners: 1) a "main effects model" wherein personality yields tonic discrepancies in the immune system; 2) a "predisposition model" wherein effects of stressors on the immune system are dependent on personality; 3) a "common cause model" wherein immune function and personality are related attributable to a common determinant (e.g., gene linkage). Furthermore, the impact of neuroticism on psychosocial mediators may have adverse effects on the immune system. ${ }^{11}$ These psychological mediators comprise the followings:

\section{Mood}

Neuroticism is strongly related to negative mood. Also, the negative mood has been found to influence the immune system; generally. Although it is associated with less functional, enumerative, and in vivo immune parameters, ${ }^{12}$ depression might be 
correlated with the elevated secretion of proinflammatory cytokines. ${ }^{13}$ Moreover, induction of acute negative mood may lead to more lymphocyte numbers and activity, lasting for a short while, especially for NK cells. ${ }^{12}$

\section{Stressors and life events}

As reported by some of the recent studies, neuroticism can play a crucial role in moderating the effects of stressors on the immune system. However, the neuroticism impacts on the immune system may be mediated by stressors. In other words, neuroticism might affect the immune system by changing the quality and quantity of stressors. Therefore, personality not only does lead to the presence of stressors (i.e., exposure) but also influences the response to stressors (i.e., reactivity). ${ }^{11}$ Bolger and Schilling ${ }^{14}$ investigated the dependence of the relationship between neuroticism and negative mood on the exposure and reactivity separately. Based on their results, exposure and reactivity accounted for roughly 14 and $29 \%$ of the relationship between neuroticism and negative mood, respectively.

\section{Health behavior}

The immune system can be negatively influenced by health behaviors, including using alcohol or other drugs, insufficient sleep, smoking, or lack of physical activity. Such unhealthy behaviors are observed at higher levels of neuroticism. ${ }^{15,16}$

In sum, these results developed a superior understanding of how individuals respond to the COVID-19 pandemic according to the relation of neuroticism with personal hygiene practices, immune system, and risk perception. Thus, the clinicians should highlight the significance of neuroticism in the prediction of individuals' protective behaviors during the COVID-19 pandemic. In this respect, the neuroticism evaluation via short self-report scales or new technologies such as digital footprints (e.g., likes on social media platforms) could contribute to screening many individuals with minimal attempt and launching personality-tailored prevention campaigns (e.g., bombarding individuals of high neuroticism with information about how to pass through the cruel cycle). ${ }^{17}$

\section{Acknowledgments \\ None.}

\section{Conflicts of Interest}

The author has no potential conflicts of interest to disclose.

\section{ORCID iD}

Mohsen Khosravi https://orcid.org/0000-0003-2970-6309

\section{REFERENCES}

1. Brooks SK, Webster RK, Smith LE, Woodland L, Wessely S, Greenberg $\mathrm{N}$, et al. The psychological impact of quarantine and how to reduce it: rapid review of the evidence. Lancet 2020;395:912-920.

2. Turiano NA, Pitzer L, Armour C, Karlamangla A, Ryff CD, Mroczek DK. Personality trait level and change as predictors of health outcomes: findings from a national study of Americans (MIDUS). J Gerontol B Psychol Sci Soc Sci 2012;67:4-12.

3. Cohen S, Janicki-Deverts D, Crittenden CN, Sneed RS. Personality and Human Immunity. In: Segerstrom SC, Editor. The Oxford Handbook of Psychoneuroimmunology. Oxford: Oxford University Press, 2012, p.146169.

4. Khosravi M. Perceived risk of COVID-19 pandemic: the role of public worry and trust. Electron J Gen Med 2020;17:em203.

5. Harper CA, Satchell LP, Fido D, Latzman RD. Functional fear predicts public health compliance in the COVID-19 pandemic. Int J Ment Health Addict 2020;1-14.

6. Merino H, Senra C, Ferreiro F. Are worry and rumination specific pathways linking neuroticism and symptoms of anxiety and depression in patients with generalized anxiety disorder, major depressive disorder and mixed anxiety-depressive disorder? PLoS One 2016;11:e0156169.

7. Zajenkowski M, Jonason PK, Leniarska M, Kozakiewicz Z. Who complies with the restrictions to reduce the spread of COVID-19?: personality and perceptions of the COVID-19 situation. Pers Individ Dif 2020;166:110199.

8. Abdelrahman M. Personality traits, risk perception, and protective behaviors of Arab residents of Qatar during the COVID-19 pandemic. Int J Ment Health Addiction 2020 [Epub Ahead of Print].

9. Cowling BJ, Ng DM, Ip DK, Liao Q, Lam WW, Wu JT, et al. Community psychological and behavioral responses through the first wave of the 2009 influenza A (H1N1) pandemic in Hong Kong. J Infect Dis 2010; 202:867-876.

10. Aronson E. Fear, denial, and sensible action in the face of disasters. Soc Res Int Quart 2008;75:855-872.

11. Segerstrom SC. Personality and the immune system: models, methods, and mechanisms. Ann Behav Med 2000;22:180-190.

12. Futterman AD, Kemeny ME, Shapiro D, Fahey JL. Immunological and physiological changes associated with induced positive and negative mood. Psychosom Med 1994;56:499-511.

13. Connor TJ, Leonard BE. Depression, stress and immunological activation: the role of cytokines in depressive disorders. Life Sci 1998;62:583606.

14. Bolger N, Schilling EA. Personality and the problems of everyday life: the role of neuroticism in exposure and reactivity to daily stressors. J Pers 1991;59:355-386.

15. Allen MS, Walter EE, McDermott MS. Personality and sedentary behavior: a systematic review and meta-analysis. Health Psychol 2017;36: 255-263.

16. Gale CR, Hagenaars SP, Davies G, Hill WD, Liewald DC, Cullen B, et al. Pleiotropy between neuroticism and physical and mental health: findings from 108038 men and women in UK Biobank. Transl Psychiatry 2016;6:e791.

17. Matz SC, Kosinski M, Nave G, Stillwell DJ. Psychological targeting as an effective approach to digital mass persuasion. Proc Natl Acad Sci U S A 2017;114:12714-12719. 